\title{
OLHARES DIANTE DE UMA EDUCAÇÃO DEMOCRÁTICA
}

\author{
Silvia Cristina Barbosa da Silva ${ }^{1}$
}

RESUMO: O acesso ao ensino universitário nem sempre é tão simples quando se trata de alunos advindos da escola pública. Por outro lado, iniciativas de uma educação não-formal facilitam a trajetória de jovens e adultos de camadas menos favorecidas ao ensino superior. O presente texto visa refletir sobre questões educacionais na perspectiva de uma educação democrática. Trata-se de um relato de experiência, no qual tratarei de dois momentos, sobre uma educação que considero diferenciada. O primeiro refere-se à minha trajetória para chegar à universidade pública diante de um espaço educacional democrático através da ONG Centro de Investigações de Metodologias Educacionais Alternativas Conexão (CIMEAC). Tal projeto estrutura-se em um Curso Pré-Vestibular ("Cursinho Popular") localizado no município de Ribeirão Preto - São Paulo. O segundo se dá após o ingresso na Universidade Estadual Paulista "Júlio de Mesquita Filho" (Campus de Araraquara) no curso de Pedagogia através da experiência com o Grupo de Estudos e Pesquisas Filosofia para Crianças (GEPFC). Em ambos espaços educacionais tanto o educador como o educando vivenciam experiências pedagógicas significativas no processo de formação, buscando assim uma ampliação do conhecimento, bem como uma possível emancipação do sujeito.

Palavras-chave: Educação não-formal; Cursinho Popular; Experiência.

ABSTRACT: The access to University studies is not as simple when concerning students coming from the public educational sistem; on the other hand, iniciatives on a non-formal education facilitate the young and adult people's path towards higher education. This paper aims to reflect on educational issues on a route of democratic education. This is an experience report, in which I will relate two moments about an education that I consider differentiated. The first relates to my own journey to reach the public university on a democratic educational space through CIMEAC NGO - Centre for Educational Research Methodologies Alternatives Connection in which is structured in a "Popular Preparatory Courses" in the city of Ribeirão Preto, São Paulo. The second occurs after enrolling at São Paulo State University - UNESP (Campus Araraquara) in the course of Pedagogy through the experience with the Group of Studies and Research Philosophy for

\footnotetext{
${ }^{1}$ Mestranda em Educação Escolar pela Universidade Estadual Paulista "Júlio de Mesquita Filho" (UNESP) - Campus de Araraquara. Graduada em Pedagogia pela UNESP - Araraquara. Atua no Grupo de Estudos e Pesquisas Filosofia para Crianças (GEPFC).
} 
Children (GEPFC). In both educational spaces both, the educator and the student, have significant experiences on the learning process, thereby seeking for an improvement in knowledge as well as a possible emancipation of the subject.

Keywords: Non-formal Education; Popular Preparatory Courses; Experience.

\section{INTRODUÇÃO}

Ter a instituição escolar como um direito de todo cidadão não a isenta de seus próprios interesses. Freitag (1980) argumenta que toda educação expressa uma doutrina pedagógica impondo uma filosofia de vida que é transmitida através da escola. Com isso podemos questionar se estamos aceitando tais princípios, tornando-nos submissos, ou se estamos em um caminho de luta e resistência. Podemos pensar tal questão na trajetória de muitos jovens e adultos de camadas menos favorecidas no acesso ao ensino superior. Muitos desses jovens buscam espaços alternativos e democráticos de ensino como os Cursos Pré-Vestibulares ("Cursinhos Populares"). O presente artigo tem como princípio refletir sobre questões educacionais entre um ensino tradicional e um democrático. Desse modo, venho destacar minhas vivências e percepções através do Cursinho Popular Conexão e do Grupo de Estudos e Pesquisas Filosofia para Crianças (GEPFC) da Universidade Estadual Paulista "Júlio de Mesquita Filho" (Campus de Araraquara). Penso que essa temática merece ser investigada, uma vez que representa a luta de muitos jovens na busca pelo ensino superior público. Considero que essas duas vivências tendem a uma educação democrática por situá-las na educação não-formal. Vale ressaltar que o artigo não tem o propósito de criticar o ensino tradicional, uma vez que esse possui sua historicidade e identidade: proponho apenas uma reflexão sobre os aspectos de uma educação democrática.

De acordo com Gohn (2006), a educação não-formal está conceituada no campo da Pedagogia Social, na qual trabalha com a coletividade preocupando-se com os processos de aprendizagens e saberes coletivos. Desse modo, a 
educação não-formal se dá de forma participativa em grupos que lutam e resistem por alguma causa, tendo como princípio a justiça social através do conhecimento educacional, o que origina um sentimento de pertencimento e identidade entre os indivíduos nesse contexto. Por outro lado, a educação formal se caracteriza pela educação tradicional por suas estruturas normatizadas, currículo central e hierarquização, orientadas através de normas nacionais. Para tanto, essa educação encara o aluno como um ser passivo e o silencia com o ensino de forma demarcada e compensatória.

Freitag (1980) evidencia os pressupostos de Bourdieu e Passeron, pois os dois concebem a sociedade através de sua historicidade e criticam a sociedade capitalista, considerando esta uma estrutura social que decorre da divisão do trabalho: assim, a educação, para eles, é um meio de reprodução da cultura, bem como da estrutura de classes. Esse fato mostra que tanto o poder como o privilégio são transmitidos de forma hereditária entre os indivíduos, originando uma aparência de neutralidade. Assim, as ideologias da classe dominante são transmitidas às demais classes que internalizam como se pertencessem à elas, estes aceitam essa sujeição de maneira natural formando um habitus nos indivíduos.

Tal naturalidade é concebida quando o indivíduo acredita na diferença entre os homens, ou seja, que um indivíduo seja mais habilidoso que o outro, e que as mesmas chances lhe são oferecidas. Então, não alcançar o sucesso profissional está associado a um desinteresse e a uma incapacidade do próprio sujeito e não à falta de oportunidade, ou seja, de acesso a uma escola que nem sempre foi acessível a toda população. Diante disso, muitos indivíduos sentem-se culpados por tal fracasso, aceitando esse fato como algo natural, como um destino predeterminado. Em oposição a essa educação tem-se a educação não-formal que questiona e busca a consciência por uma educação libertadora: esta consiste em uma recusa do discurso da educação formal, propondo a possibilidade de uma educação emancipatória. Para isso seria necessária uma luta interna como um deslocamento do pensar: este descolamento se faz presente na busca pelo "ser mais", que Freire (1977) define como a indagação do homem, o questionamento 
da desumanização e da opressão. Essa conscientização faz com que o homem busque o "ser mais", pois o ser menos sofre a violência da opressão. Resistir à alienação é buscar ser mais, é a consciência da violência de ser oprimido e ainda assim lutar para superá-la. Tal superação não se define em sair da condição de oprimido para tornar-se um opressor: o desafio, pelo contrário, consiste na busca por uma relação humanizada, pela liberdade de si e também de seus opressores. O contrário seria a aceitação e a criação de um opressor dentro do próprio oprimido.

A educação não-formal é construída em espaços diferenciados, de modo que o processo de ensino-aprendizagem se dá através do outro, podendo ser educadores, mediadores, ou seja, pela interação. Esse pressuposto se afirma em Freire (1998) quando o pedagogo diz que ensinar não é transferir conhecimento, e sim criar possibilidades para o seu próprio crescimento, o que possibilita criticidade e autonomia para o sujeito. Na escola não-formal há um envolvimento com a comunidade e com a cultura local, com uma relação horizontalizada entre professor e aluno, onde a aprendizagem é concebida em processo, o que a torna mais significativa, ampliando a experiência do sujeito, pois de acordo com Bondía (2002, p. 21):

\footnotetext{
A experiência é o que nos passa, o que nos acontece, o que nos toca. Não o que se passa, não o que acontece, ou o que toca. $A$ cada dia se passam muitas coisas, porém, ao mesmo tempo, quase nada nos acontece. Dir-se-ia que tudo o que se passa está organizado para que nada aconteça.
}

Essa experiência que nos toca é mais comum em um ambiente educacional diferenciado, onde existe uma relação igualitária entre professor e aluno e essa possibilidade se dá na educação não-formal. Para Gadotti (2005), o conhecimento serve primeiramente para nos conhecer melhor, a nós mesmos e a todas as nossas circunstâncias, e adquirir o conhecimento com algo que nos acontece penso ser de fundamental importância para o educando, pois amplia o olhar da importância da aprendizagem. 


\section{OLHAR EXTERNO: ANTES DO INGRESSO NA UNIVERSIDADE}

Para tanto, destaco minha trajetória para o ingresso à universidade pública com uma experiência muito significativa para minha formação enquanto educadora através do Cursinho Conexão "cursinho popular" um espaço democrático estruturado em um curso preparatório para o vestibular. Porém, falar sobre experiências pessoais é um traduzir-se, e isso nem sempre é simples, mas relatar aquilo que nos tocou, que nos aconteceu é fascinante. Esse traduzir provoca um descolamento que transforma, que nos tira de um lugar e nos leva a outro, como se fosse um olhar de fora para dentro, ou seja, uma reflexão. Exprimir essa experiência num único texto me parece insuficiente pois experiências são permanentes em nossas vidas.

Freqüentei o grupo Conexão no ano de 2008 e 2009 e inicialmente a procura foi pela proposta diferenciada de ensino, pois vivenciei métodos tradicionais e não alcançava a aprovação no tão disputado vestibular. Por isso a busca por um método alternativo, ligado a um forte desejo de cursar o ensino superior público e por acreditar que este era um direito possível de ser alcançado. $E$ isso sempre foi algo muito motivador, mesmo sabendo que exigiria tempo, esforço, dedicação e angústia em lidar com a incerteza, uma vez que a avaliação do vestibular é anual, e a não aprovação seria mais um ano de estudo.

Desse modo, o que me movia nessa trajetória era a consciência dessa situação de exclusão. Tal consciência era transformada em estímulo na busca pelo conhecimento em uma futura conquista. Porém, a estrutura do cursinho ultrapassa um método diferenciado. Este espaço democrático propõe a relação entre professor e aluno isenta de hierarquia, o que coloca o jovem trabalhador e o estudante em uma posição de reflexão e questionamento sobre sua atuação na sociedade, uma vez que nesse meio ele ganha visibilidade e voz. Essa oportunidade favorece a luta na busca pelo "ser mais". 
A própria estrutura física do local auxilia no diálogo: as aulas são organizadas em círculos, o que representa uma afirmação da relação de igualdade entre o grupo, como também na influência dos laços de amizade com os demais alunos, pois tínhamos os mesmos propósitos, o que gerava um sentimento de pertencimento e identidade e isso nos sustentava na busca pelo conhecimento. $O$ currículo organizado em módulos possui a duração de três a quatros semanas, com os temas diversificados, como por exemplo: Água; Arte e Cultura; Ciência e Tecnologia; Direitos Humanos; Economia; Energia; Esporte; Guerra; Transporte entre outros. Dessa forma, os conteúdos de Exatas, Humanas e Biológicas eram incluídos em todos os módulos.

Assim, estudávamos em pequenos grupos e depois explicitávamos aos demais em uma troca de experiência muito relevante à aprendizagem. Muitas vezes essas aulas eram organizadas em dinâmicas, o que tornava os conteúdos ainda mais instigantes com uma aprendizagem mais significativa e prazerosa. Considero o desejo de ingressar na universidade como um devir, isto é, um movimento que visa à transformação, um acontecimento, um caminho que tenderia a mudar a vida de cada aluno que ali frequentava, uma vez que durante o cursinho a maioria dos participantes trabalhavam e a aprovação no vestibular significaria a renúncia deste trabalho para um investimento pessoal a longo prazo, o que nos proporcionaria uma perpesctiva de vida diferenciada. Para tanto, essa trajetória durante o cursinho através desse devir, esse caminho incerto que vivenciávamos era uma disposição de cada aluno em uma abertura para a novidade que estaria por vir.

A proposta de ensino, a metodologia diferenciada, as discussões, o conhecimento, o currículo oculto e a experiência nos levariam a esse lugar ainda duvidoso. Essa trajetória não oferece certificado, todavia tais experiências dispensam qualquer tipo de certificação. Os alunos sabiam que a intenção do cursinho não era o imediatismo na aprovação do vestibular. Desse modo, a aprovação seria uma consequência, um resultado de um processo sendo insuficiente em apenas um ano letivo, pois ao mesmo tempo que aprendíamos os conteúdos, internalizávamos a consciência da posição de oprimidos. Diante disso, 
Freire (1977) na Pedagogia do oprimido menciona que esta não pode ser elaborada por opressores, e sim pelos próprios oprimidos: logo a relação dentro do grupo Conexão se faz entre pares, pessoas advindas de uma classe oprimida que visa a libertação e a valorização do conhecimento. Penso que, os próprios oprimidos precisam adquirir o conhecimento para ter ação e a consciência da estruturação de uma pedagogia diferenciada, voltada aos oprimidos. Portanto esta ação vem da desumanização e da consciência coletiva da busca pela liberdade. Em relação a essa liberdade, Freire (1977, p. 35) menciona que:

\begin{abstract}
A liberdade, que é uma conquista, e não uma doação, exige uma permanente busca. Busca permanente que só existe no ato responsável de quem a faz. Ninguém tem liberdade para ser livre: pelo contrário, luta por ela precisamente porque não a tem. Não é também a liberdade um ponto ideal, fora dos homens, ao qual inclusive êles se alienam. Não é ideia que se faça mito. É condição indispensável ao movimento de busca em que estão inscritos os homens como seres inconclusos.
\end{abstract}

Essa inconclusão se define na luta pelo ser mais, e a condição da busca pela liberdade é visível no grupo pela interação entre alunos e professores. Esse fato pode ser demonstrado por uma certa autonomia por parte de muitos alunos, pois em situações de ausência de professor a aula acontecia, sendo também muito proveitosa. Recordo-me do discurso de um dos professores argumentado que nós alunos não estavamos em posição muito distantes, uma vez que eles preparavam as aulas estudando os conteúdos para ser compartilhado, portanto estávamos muito próximo deles em relação a possibilidade de adquirir conhecimento, e isso era um grande incentivo na resistência de nossa luta, na busca incessante pelo conhecimento.

Os conteúdos estrututados em módulos temáticos eram justamente o que seria cobrado nos principais vestibulares, porém não estudávamos somente esses assuntos. Um extenso currículo nos era oferecido, conceitos de pensadores eram propostos ampliando assim nossa reflexão, como, por exemplo, o conceito de capital cultural, de Pierre Bourdieu, que vinha ao encontro de nossa própria 
condição, pois disputávamos vagas na universidade com jovens com capital cultural mais elevado que o nosso. Havia uma troca de experiências com demais cursinhos da cidade, bem como com a UGT (União Geral dos Trabalhadores), também no município de Ribeirão Preto, onde participávamos de discussões sobre a vida e a obra do intelectual Antonio Gramsci. Do mesmo modo, o prórpio Paulo Freire nos foi apresentado para a discussão do conceito de opressão. Conceitos estes que internalizávamos como um grande estímulo para continuar a lutar, pois desistir seria permanecer na estabilidade da nossa condição social com nenhuma possibilidade de mudança ou mobilidade social. Viagens, filmes, discussões políticas estavam inseridos em nosso currículo de foma muito natural, a participação em fóruns regionais entre os cursinhos nos dava a dimensão de que estávamos vivenciando experiências semelhantes a outros jovens. Férias eram períodos de integração entre o grupo, pois selecionávamos filmes a serem discutidos e o diálogo sempre esteve muito presente no grupo, estruturando assim um espaço democrático. Nossos objetivos eram embasados por nossa insatisfação, que nos instigava na busca por um caminho diferente daquele comum que estávamos predestinados. Como a aprendizagem não se restinge aos conteúdos do vestibular, nossa leitura de mundo torna-se ampla nesse espaço educacional.

\section{OLHAR INTERNO: APÓS O INGRESSO NA UNIVERSIDADE}

A aprovação no vestibular chegou e assim ingressei no curso de Pedagogia - Licenciatura na Universidade Estadual Paulista "Júlio de Mesquita Filho" (Campus de Araraquara) no ano de 2010, pois a área da educação sempre me instigou. Na disciplina de Filosofia da Educação I, ministrada pela Profa ${ }^{\text {. Dra }}$. Paula Ramos de Oliveira, no primeiro semestre do curso deparei-me com a aula em círculo, e isso me encantou porque me senti num espaço semelhante ao do Projeto Conexão. Assim esta mesma professora nos apresentou o Grupo de Estudos e Pesquisas Filosofia para Crianças (GEPFC). Participar do Grupo foi e é uma experiência inexplicável, uma vez que é pautado em uma educação dialógica 
bem como a proposta de ensino do Projeto Conexão. Participei como monitora do Projeto de Extensão do GEPFC durante três anos, sendo este realizado em duas escolas do município de Araraquara. A proposta de filosofia para crianças é seguida pela UNESP - Campus de Araraquara, Universidade do Estado do Rio de Janeiro (UERJ) e Universidade de Brasília (UnB). Nesses espaços a educação é

questionada e refletida de maneira muito apurada.

A Filosofia para Crianças foi criada pelo norte americano Matthew Lipman. Esta fundamenta-se no princípio da comunidade de investigação, visando à internalização do pensamento reflexivo através do diálogo. A possibilidade dessa prática alternativa de educação nos coloca diante de uma concepção diferenciada de educação, bem como a própria infância, pois segundo Kohan (2007) devemos nos esvaziar daquilo que acreditamos conhecer sobre educação, infância e jovem para nos abrirmos a novos saberes, e isso nos permite experienciar a infância de forma horizontal. A abertura de um pensamento questionador nos permite encarar a educação com um olhar transformador, na possibilidade de ser praticada em uma proposta dialógica, onde a aprendizagem torna-se recíproca, tendo a relação professor e aluno de maneira igualitária. De acordo com minha experiência como monitora da prática em filosofia para crianças, presenciei um envolvimento por parte dos alunos, já que estes não se permitiam ficar calados, e a escuta entre o grupo era de fundamental importância. Nesse contexto, um questionamento muito comum entre os membros do GEPFC era sobre a própria prática, isto é, a filosofia "para" e a "com" crianças. Considera-se o "para" na estrutura do material, na proposta inicial para a discussão filosófica e o "com" se define no contato direto com o aluno através do olhar, do ouvir, isto é, na abertura do pensamento através do diálogo. Tal abertura promove uma descontrução do que pensávamos, pois dialogar com a infância e com a educação de maneira geral é dialogar com um devir, que desconstrói e constrói novos pensamentos. 


\section{CONSIDERAÇÕES FINAIS}

Diante disso, penso que o grupo Conexão vivencia um "para" e um "com" frente a uma educação alternativa, bem como o GEPFC. Este "para" revela uma doação de si frente ao outro, estruturada em iniciativas de um currículo diferenciado e reflexivo voltado para uma educação popular, questionadora e dialógica, enquanto o "com" fixa toda a prática de ensino com o jovem trabalhador, que busca compreender os interesses implicítios da educação, na crença de que espaços democráticos de ensino impulsionem uma perspectiva de vida no caminho ao ensino superior. A resistência consiste em uma permanente busca pelo "ser mais". Finalizo esse texto argumentando que tanto o olhar de fora quanto o olhar de dentro consistem em acreditar na potência de uma educação democrática.

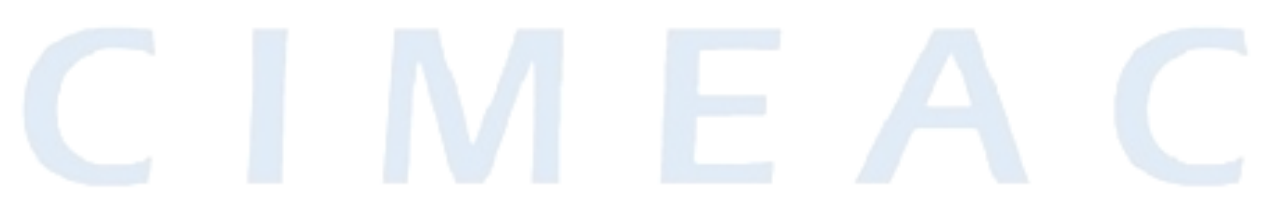

\section{REFERÊNCIAS BIBLIOGRÁFICAS}

BONDÍA, Jorge Larrosa. Notas sobre a experiência e o saber de experiência. Revista Brasileira de Educação, Campinas, n. 19, p. 20-28, jan/fev/mar/abr. 2002.

FREIRE, Paulo. Pedagogia da Autonomia: saberes necessários à prática educativa. São Paulo: Paz e Terra, 1999.

FREIRE, Paulo. Pedagogia do Oprimido. Rio de Janeiro: Paz e Terra, 1977.

FREITAG, Bárbara. Escola, Estado e Sociedade. São Paulo: Moraes, 1980.

GADOTTI, M. A questão da educação formal/não-formal. Institut International des Droits de I'Enfant (IDE), Sion (Suisse), p. 1-11, out. 2005.

GOHN. Maria da Glória. Educação não-formal, participação da sociedade civil e estruturas colegiadas nas escolas. Ensaio, Rio de Janeiro, v. 14, n 50, p.27-38, jan./mar. 2006. 
Educação não-formal na pedagogia social. In: I CONGRESSO INTERNACIONAL DE PEDAGOGIA SOCIAL, São Paulo, v. 1, mar. 2006. Disponível

em<http://www.proceedings.scielo.br/scielo.php?script=sci arttext\&pid=MSC00000 00092006000100034\&lng=en\&nrm=abn>. Acesso em: 08 de out.2013.

KOHAN, Walter Omar. Infância, estrangeiridade e ignorância. Belo Horizonte: Autêntica, 2007. 